\title{
ACRL in Atlanta
}

\section{ACRL's programs at the ALA Annual Conference}

A

LA's 121st Annual Conference was held June 13-19, 2002, in Atlanta. Total conference attendance was 21,130 , including members, exhibitors, exhibits only, and guests. $\boldsymbol{E} \boldsymbol{d}$. note: Thanks to the ACRL members who summarized programs to make tbis reportpassible.

\section{Learning communities}

The ACRL President's Program, "Transformational Learning Communities: Claiming Our Future," featured Barbara Leigh Smith, codirector of the Pew Charitable Trusts' National Learning Community Project and founding director of the Washington Center for Improving the Quality of Undergraduate Education.

Smith, who has written extensively on learning, presented an overview of learning communities, including how they are defined ("a variety of approaches that link or cluster classes during a

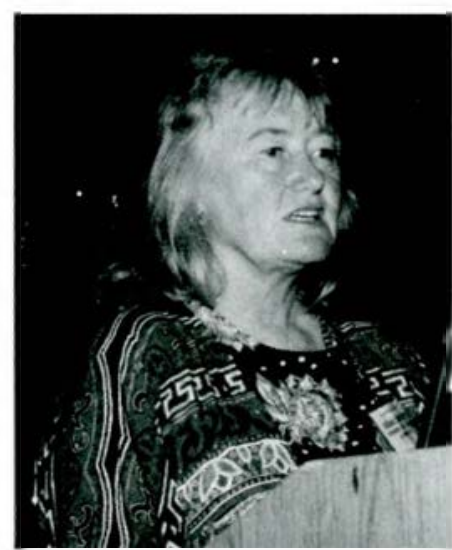

Featured speaker Barbara Leigh 5 mith speaks of learning communities and the role of libraries as "spring boards," not simply "gatekeepers" for higher education. are developing learning communities; Randy Burke Hensley, head of public services at the University of Hawaii Libraries, discussed learning communities in large colleges and universities; and Joan K. Lippincott, associate executive director of the Coalition for Networked Information (CNI), discussed how technology can enhance learning communities and bring people together around a common goal, theme, or endeavor.

A poster session followed the program featuring learning communities that have been implemented at various academic institutions. Displays featured research guides, classes, and tutorials that libraries have created to encourage information literacy; descriptions of distance learning programs in library science and media studies; and the development of library liaison programs. - LeslieMadden, Georgiven term, often around an interdisciplinary theme, that enroll a common cohort of students"), their historical development, and the role of libraries as "spring boards," not simply "gatekeepers" for higher education.

Following Smith's presentation, a panel of responders spoke on various aspects of learning communities: Theresa S. Byrd, director of libraries at Ohio Wesleyan University, discussed how small liberal arts and community colleges gia Institute of Technology, leslie.madden@ libralygated bedu

The African American Studies Librarians Section (AFAS) and the Rare Books and Manuscripts Section (RBMS) cosponsored a presentation on African American special collections from the perspective of three institutions.

\section{Creating new African American special collections}


Taronda Spencer (Spelman College) was the moderator for the program.

Panelist Randall K. Burkett (Emory University) explained that the focus of the African American collection at Emory University is black print culture, expatriate African American writers and artists, and the post-Civil Rights movement.

Lucelia Flood-Partridge (Auburn Avenue Research Library on African-American Culture and History [AARL] in Atlanta) described the AARL, which began as a small collection of books on Negro history in 1934. Some of its notable collections are the Andrew Young Collection and the records of the Atlanta NAACP. Although the foundation of the collection is the African American experience in Atlanta, it has expanded to a global perspective.

Pearl Woolridge (Broward County African American Research Library and Cultural Center [AARLCC] in Ft. Lauderdale) announced that the AARLCC is scheduled to open on October 26, 2002. It will document the "maritime" Underground Railroad and how peoples of Jamaican, Haitian, Cuban, and African descent have contributed to the fabric of Ft. Lauderdale society. The collection will have more than 750,000 items.-Angela J. Wright, Universityof Alabama, ajwinght@bama.ua.edu

\section{Shamanism and librarianship}

Speakers in this session addressed various aspects of a more unusual, less pragmatic topic than your standard library conference fare "Shamanism: Implications for Re-Visioning Librarianship" was sponsored by the Anthropology and Sociology Section (ANSS). Presenters offered various interpretations on why shamanism attracts contemporary, technologically advanced, information-driven cultures.

Delia Easton (Centers for Disease Control and Prevention) noted that earlier cultures were sociocentric in their shamanistic practices. Our more egocentric societies employ shamanism along with western psychotherapy and biomedicine in private rather than public spaces. The Internet hosts countless Web sites for latterday shamans from Sedona, Arizona, and other New Age locales.

Gary Laderman (Emory University) stated that shamanism defies definition. In recent times shamanism became democratized. Growing numbers of people simply proclaim themselves shamans. A case might be made that fu- neral directors are modern counterparts of shamans because they mediate between life and death for those mourning the loss of loved ones. The vast terrain of shamanism that encompasses folkways, biomedicine, and populat culture overwhelms and frustrates academicians in the 21st century.

Sydney Pierce (Catholic University of America) closed the session. As a professor of library science, she made the connection between shamans and librarians. Librarians emulate shamans because we mediate between a repository of knowledge from the past and make it accessible to the living. We make sense out of chaotic accretions of old and new information for our clients and patrons. She encouraged us to really examine how our users find information, because it often cleviates from accepted practices, and urged us to make adjustments to ease/heal their anxieties.-JoEllen Broome, Georgia Soutbern Unitersity, jbroome@ grouledu

\section{The social psychology of faculty/ librarian relationships}

An enthusiastic standing-room-only audience attended "Games Academics Play," the program presented by the Education and Behavioral Sciences Section (EBSS). The first presenter, John Budd (School of Information Science and Learning Technologies of the University of Missouri, Columbia), set up a framework through which to answer the question, "How do [librarians] strategize to win?" Budd suggested that we need to develop a clear understanding of the scholarly apparatus within academic disciplines and to focus on librarians' specific and unique contributions to the ultimate objects of the "game": academic inquiry and student learning and development.

Sociologists Mindy Stombler (Georgia State University) and Lars Christiansen (Augsburg College) reported the results of surveys, focus groups, and interviews on faculty-librarian relationships. Overall sources of disconnection include: different functions served (production versus service); lack of faculty knowledge of librarians' skills; physical separation; faculty perception that librarians lack knowledge of specific academic areas and their methodology; and information technology that "frees" teaching faculty from dependence on librarians.

Suggestions for librarians to overcome these disconnections include: proactive, personalized 
contact; gaining substantive knowledge of academic disciplines; and socializing new faculty members early regarding potential library contributions.

Psychologist James Emshoff (Georgia State University) presented the perspective of a "naïve" faculty member who respects librarians and is baffled by the expressed need to improve relationships. He pointed out that the faculty members might avoid the library and librarians because of bewilderment at the pace of technological change and reluctance to express ignorance. Emshoff stressed that focusing on the differences in skills between teaching faculty and librarians could enhance collaboration and communication. - Lyn Thaxton, Georgia State University, libml@@langategsu.edu

\section{Literary research instruction}

"Teaching Literary Research: Challenges in a Changing Environment," a program cosponsored by the Literatures in English Section (LES) and the Instruction Section (IS), offered a lively discussion on research instruction in the field of literary studies.

The program was moderated by Steven Harris (University of Tennessee), and the panelists were James K. Bracken (Ohio State University), James L. Harner (Texas A\&M University), Helene C. Williams (Harvard University), and William A. Wortman (Miami University Ohio).

The panel addressed several problems in teaching literary research today, including the difficulty in establishing collaborative relation-

\section{Annual Conference audiocassettes available}

Audiocassettes of selected ACRL programs from the 2002 ALA Annual Conference in Atlanta are available. Each program consists of two cassettes for $\$ 28$, unless otherwise noted.

- Games Academics Play: Mastering the Social Psychology of Faculty/Librarian Relationships. Order no. ALA206

- E-Research Companies: ValueAdded or Virtually Redundant? Order no. ALA207

- Teaching Literary Research: Challenges in a Changing Environment. Order no. ALA211

- Librarians in the Big Leagues: Are Your Ready for the Teaching Academy? Order no. ALA213

- Minding the Generation Gap: Learn How to Communicate and Work Together Across Generations. Order no. ALA215

- Mission Brief: The Research Legacies of Missionary Literatures, 3 cassettes, $\$ 42$. Order no. ALA226

- Will the Real Customer Please Stand Up? Designing Services for 21st Century Users, 1 cassette, $\$ 14$. Order no. ALA227

- The Emergence of Digital Scholarship: New Models for Librarians, Archivists and Iumanists. Order no. ALA234
- Pirates on the Commons: Legal and Political Assaults on Information Access by the Expanding Domain of Copyright. Order no. ALA236

- The Documents of September 11 th and the Search for Stable Ground, 1 cassette, \$14. Order no. ALA237

- Pornography in Libraries: Sexual Harassment? I cassette, \$14. Order no. ALA238

- Shamanism: Implications for Revisioning Librarianship. Order no. ALA241

- Building Premier Learning Communities: Strategies for Successful Library Involvement. Order no, ALA243

- Old, New, Borrowed and Blue: Science and Technology Intellectual Property Issues in the Digital Age. Order no. ALA264

- Transformational Learning Communities: Claiming Our Future. Order no. ALA266

Audiocassettes for other ALA programs are also available. Call in or fax your order to Teach 'Em, 74-923 Hovley Lane East, Suite 250, Palm Desert, CA 92260; (800) 776-5454, fax: (760) 773-9671 (credit cards only); e-mail: info@teachem.net; Web: www.teachem.net/ ala. You may pay by check (payable to Teach 'Em) or credit card (VISA, MC, AMEX). 
ships with faculty (many of whom lack expertise in new electronic resources), student reliance on "prepackaged" research tools that mask the actual processes and sources of traditional research, and a focus on technology and formats over content.

Panelists offered various conceptualizations of information literacy in an attempt to define the essential goals of literary research instruction. A core list of standards or resources can serve as a starting point for discussion with faculty and administrators, but most seemed to agree with Wortman that we probably need to "reinvent the methods course" to reflect a renewed interest in historical bibliography and to acknowledge the impact of the new electronic tools.

Harner warned against librarians assuming the role of the "glorified assistant" in this context. Ideally, librarians and teaching faculty should set goals and design courses together, so that expertise in both the process and content of research is integrated into instruction in literary research methods.-Jeanne Pavy, University of New Oreans, jpavy@uno.edu

\section{Ethical dilemmas and libraries}

The program "Ethical Dilemmas and Libraries: An Analytic Model Applied to the 'Without Sanctuary' Exhibit," sponsored by the ACRL Committee on Ethics, was as thoughtful as it was provocative.

John Banja (Emory University Center for Ethics) analyzed from an ethical perspective an Emory University/Martin Luther King Jr. National Historic Site exhibit of lynching photographs. He weighed library values of freedom of access and intellectual freedom against the potential harm that exhibiting such photographs could cause.

Banja concluded that these values are well intentioned by librarians but that we are being naive when we think of ourselves as representing a neutral viewpoint. The decision of whether to show the materials, how to show the materials, how to describe the contents of the exhibit, and figuring out what the exhibit means all require the librarian to have an opinion about the value of the materials.

For example, the tone of the lynching exhibit is very somber, in part because the curator painted the walls of the exhibit space black. The need for somberness reflects the values of the library, the community for which the ex- hibit is being mounted, and other groups involved in the exhibit.

Banja concluded that the mounting of this exhibit successfully balanced showing the truth of our past while not recreating it.Frances Maloy, Emory University, libfm@ emoryedu

\section{Pornography in libraries: sexual harassment?}

Betsy Williams (Minneapolis Public Library) began this program, sponsored by the ACRL Intellectual Freedom Committee, with a summary of a complaint made to the Equal Employment Opportunity Commission by 12 librarians working at the Minneapolis Public Library in May 2000.

The complaint was the culmination of a three-year disagreement between the librarians and the Minneapolis Public Library's administration. The librarians wanted the library to institute an Internet use policy setting clear limits on how public computers should be used by patrons of the public library who accessed the Internet.

The 12 librarians complained of being exposed to sexually explicit Web sites being accessed by patrons, resulting in inappropriate behavior in the library (including masturbation and offensive language). They claimed that unlimited and uncontrolled access to the Internet created a "hostile work environment."

For two years, the library's director refused to create a use policy, insisting that members of the public had an absolute right to access any Web site they wished. However, when the local newspaper published an article about the complaint and seven librarians filed a law suit against the library, and after the EEOC determined that the Minneapolis Public Library was guilty of exposing its staff to a "hostile work environment," the director and the library board apologized to the staff and decided to create a policy that limits the use of computers to registered library card holders and sets parameters on what is acceptable use of the computers.

L. Camille Hebert (Center for Law, Policy, and Social Science at Ohio State University) focused her discussion on the inappropriate sexual conduct of patrons, not on the access to information on the Internet. She argued that the library had a right to control the behavior of its patrons, but that the library had to tread very carefully in limiting access to adult patrons. 
Bob Corn-Revere (Hogan \& Hartson Law Firm, Washington, D.C.) insisted that libraries tioned that filters do not solve the problem; they over-block and under-block and, therefore, are not reliable in helping the library enforce its use policies. He also criticized the broadness of the EEOC determination, saying that the criterion of offensiveness of Internet Web sites to library staff as a cause of a "hostile work environment" and "sexual harassment" opens "a much broader door" where almost anything displayed on a computer screen could be used to limit access to information.

In a short question-and-answer period, the issue of national standards for what constitutes obscenity was discussed-Jack Forman, San DiegoMesa College Library, jforman@dcadcc.ca.us

\section{Digital scholarship}

"The Emergence of Digital Scholarship: New Models for Libraries, Archivists, and Humanneed to use policies for the Internet, but cau-

Morris Eaves (University of Rochester) placed the William Blake Archive (http:// www.blakearchive.org/) within Pitti's context. For two centuries Blake's works have presented problems to traditional editorial practice because of their visual and textual format. He explained that today consolidation is only possible via electronic means. An aid to the process has been a burst of volunteerism.

John Unsworth (University of Virginia) focused on the aspect of negotiation that occurs between librarians and publishers, which represents a shift from their historically adversarial roles necessitated by the digital age. While both are still concerned with selection, Unsworth feels that each should spend time fulfilling traditional roles in new ways.

Questions from the audience focused on obtaining rights to materials, funding projects, the expectation of income, and determining where we are in the publisher/author collaborationto which Unsworth answered that this still is "the incunabular stage."-Bruce Swann, University of Illinois-Urbana-Champaign, bsuannaniucedu

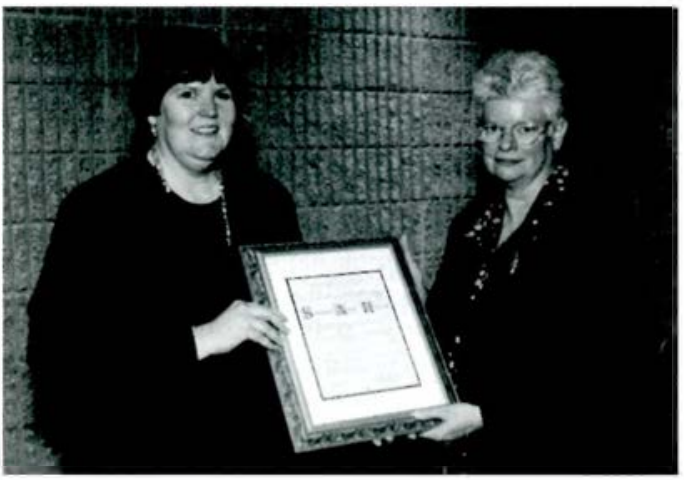

Mary Reichel presented a presidential recognition award honoring the late Sharon Hogan to Nancy John of the University of Illinois-Chicago during "A Celebration of the Life of Sharon Hogan," held at the ALA Annual Conference.

ists" was cosponsored by ACRL's Rare Books and Manuscripts and Arts Sections. Presenter Daniel V. Pitti (University of Virginia) started the program and provided the context for the other three panelists by arguing that the traditional scholarly community of archivists, creators, curators, librarians, and publishers is in the midst of a transition. Instead of each controlling a stage of scholarly work with a physical artifact as the object of control, now each contributor shares control, while the boundaries, contributions, and standards of cooperation are being negotiated.

\section{Specialized research}

The Slavic and East European Section (SEES) presented its program "What do you do when you don't have a subject specialist? or Research needs strain your library scope?" The Slavic studies academic community consists of many different constituents, who have varying degrees of access to library and archival materials.

Gregory Ference (Salisbury University) spoke candidly about the difficulties scholars at primarily teaching institutions face in conducting specialized research. In his case, his library had no Slavic collection and he drew on his own contacts at research institutions to prepare his publications. Ference noted that the introduction of Webbased catalogs has helped facilitate this research. He also gave high praise to the annual Summer Research Laboratory on Russia and Eastern Europe, held every year at the University of Illinois, which draws scholars and librarians from the United States and abroad.

Erika Banski (University of Alberta) discussed the challenge of supporting increasingly cross-disciplinary research in Russian and East European Studies. She highlighted the unique 
Slavic collection at the University of Alberta, which is especially strong in materials pertaining to Ukrainian, Polish, and Russian studies, and the extensive consortia arrangements her library has developed with institutions in Canada and the United States. Her presentation is available at http://www.ualberta.ca/ ebanski/SEES2002_Banski.ppt.

Lastly Helen Sullivan (University of Illinois at Urbana-Champaign) gave an overview of services provided by the federally funded Slavic Reference Service (http://www.library.uiuc. $\mathrm{edu} / \mathrm{spx} / \mathrm{\rho}$. The service, which began 25 years ago to help researchers across the United States locate hard-to-find Slavic materials, now includes new formats, such as Web forms for patron requests, chat components with librarians at Jagellonian University and the National Library of Russia, and an online course on Slavic bibliographic research.-Marta Deyrup, Seton Hall University, deynupma@sbu.edu

\section{Minding the generation gap}

During the University Libraries Section's program "Minding the Generation Gap: Learn How to Communicate and Work Together Across Generations," Stanley Wilder (University of Rochester) prompted attendees to ponder who might be minding the library of the future. Wilder shared charts showing the ages of librarians in ARL libraries, the largest group of which in 1986 consisted of those aged 35 to 39 . This cohort marched forward to 2000 when, at ages 50 to 54 , they still comprised the largest group. This group's retirements will require a large number of new hires, but rather than viewing this as a threat, Wilder indicated that these replacements would position libraries to adapt as they hire librarians with new skills.

Generational differences between the newer and more experienced librarians was the topic of Crit Stuart (Georgia Tech Library). Stuart, using an outline prepared by Sheila Creth, discussed a number of generations but focused on boomers and GenXers, as they contain the largest number in the workplace today. He noted differences between the groups, including boomers' need for a stable workplace and friendly worker relations compared to GenX workers who crave variety and work well on projects but value their lifestyle away from the workplace.

Stuart stressed that to manage generational differences, libraries should ensure that train- ing/development is not one size fits all, that work assignments are varied and challenging, and that managers should limit meetings and provide clear expectations and feedback.

A panel joined the speakers to respond to questions from the audience. One common theme - while acknowledging generational differences, we should not stereotype based on age but should welcome and integrate individual differences in the workplace. Speaker notes and a list of panelists are available at http:// www.ala.org/acrl/uls/uls_conf02.html-_Bob Fox, Clayton College E State University, bobfox@mail.claytonedu

\section{Mapping the future of historical scholarship about Europe}

This Western European Studies Section (WESS) program, cosponsored by ALA's Map and Geography Round Table (MAGERT), focused on exploring and supporting new directions in interdisciplinary historical research on Europe based on electronic geographical resources.

Karl Longstreth (University of Michigan) discussed the value of online geographic information in interdisciplinary research and teaching. Innovative projects, many collaborating in the Electronic Cultural Atlas Initiative, explore combined issues of space and time, using technologies such as TimeMap software. Interconnecting text, maps, and images as part of a relational database can develop a compelling narrative of a place. Longstreth said that dynamic online maps "make historical change visually meaningful," while spatial analysis may identify significant relationships.

Humphrey Southall (University of Portsmouth and the Great Britain Historical GIS Project) outlined the expansion of the Great Britain Historical GIS Project for British historical geography (including a statistical database, atlas, gazetteer, and travel accounts) from a specialized academic research project into an extensive collaborative program funded to create a national public resource providing a vision of Britain over time. To support multiple functionalities and large numbers of simultaneous users, an Oracle spatially enabled relational database-with spatial cataloguing following open metadata standard-and new visualization technologies are planned.

Moderator Richard Hacken (Brigham Young University) tied together the speakers' themes (theoretical and pragmatic) and encouraged dis- 


\section{News from the University Libraries Section}

Ed. note: For a report on the ULS program, please see "Minding the generation gap" on page 561.

\section{Chair's message}

As academic libraries become active partners in our institutions' efforts to effectively evaluate what we do, assessment is increasingly an important topic on our campuses, in our libraries, and at professional meetings. This past ALA Annual Conference was no exception to this trend.

The University Libraries Section (ULS) Standards and Guidelines Committee has been addressing this most serious of topics on our behalf for some time. Acting upon our recommendation, the ACRL Board has created a joint committee to integrate the various types of library standards into one document that could be used by every academic library.

This is a significant move in the right direction and should result in a document that will be meaningful to each of us as we look at our own services, programs, staff, and space, as well as provide us with appropriate measurements that will be significant to our parent institutions.

Following up on this effort, the ULS Executive Committce approved a joint forum with College Libraries Section (CLS) to be held at the ACRL 11th National Conference in Charlotte, North Carolina. The purpose of this forum is to discuss the development of a "tool kit" in support of the outcomesoriented standards being developed that could be adapted for every academic library, regardless of size, user population, and emphasis. A big task for sure, but one that will benefit all of us.

I invite all ULS members to participate in this forum in Charlotte. If you are not planning to attend, please share your ideas for appropriate tools that would measure what we do and its impact on students and faculty with me or the Chair of the UTS Standards and Guidelines Committee, Lori Goetsch (University of Maryland) e-mail: lgoetsch@deans.umd.edı.
We look forward to hearing your thoughts on this topic as we all begin developing effective assessment tools. Let us know what you have done in your libraries, whether it was successful or not, so that we can share our experiences and learn from each other.

As the national accrediting bodies revise their standards and focus on outcomes, academic libraries have to be active partners in showing our communities that we, too, fulfill a role that is unique on campus, and that we are part of our campus learning communities.-Louise S. Sherby, Hunter College/ CUNY, louisesherby@buntercunyedu

\section{Executive Committee}

The ULS Executive Committee met twice during the ALA Annual Conference and continued its discussion of several major ongoing policy issues, as well as addressing several new items of business. The Executive Committee welcomed its new liaison from the ACRL Board of Directors, Rita Jones (City College of San Francisco).

Notable among the ongoing issues was the activity of the ULS Standards and Guidelines Committee and its evolving work with Community and Junior College Libraries Section (CJCLS) and CLS to develop a combined set of standards for academic libraries. The committee had asked the ULS Executive Committee to endorse an approach similar to the more output-oriented and assessmentbased "Standards for College Libraries." The approach has now evolved into an effort to develop an overall set of academic library standards bridging the different academic library types.

Lori Goestch reported to the Executive Committee that the ACRL Board had taken significant steps towards establishing a unitary set of standards. She reported that the ACRL Board had charged a task force to adapt the "Standards for College Libraries" for use across all types of academic libraries, move the revised standards through the appropriate approval process, and make recommendations on implementation and support for these new standards. 


\section{(continuedfromprasiaspage)}

The ULS Executive Committee then addressed the issue of standards for branch libraries and undergraduate libraries. The committee endorsed the possibility of folding these separate sets of standards into the new overall standards and suggested that such an approach be fully considered.

Previous discussions by the Executive Committee about the creation of a membership committee culminated in formal action to establish this new committee. The Executive Committee received a report on how other ACRL sections organized this function. The ULS Communications Committee, which had previously been responsible for membership activities, also endorsed the establishment of the new committee to address membership issues.

An important new issue addressed by the Executive Committee was the decision to sponsor a new discussion group. The Executive Committee voted unanimously to support a new Urban University Libraries Discussion Group under the auspices of ULS. Information about the new group's electronic discussion list can be found at http:// www.library gsu.edu/urbanlibs/.

\section{Heads of public services}

The ULS Public Service Directors of Large Research Libraries Discussion Group, convened by Diane Strauss (University of North Carolina, Chapel Hill), addressed several diverse topics in their discussion. Ed Van Gemert (University of Wisconsin, Madison) initiated the conversation on security in branch libraries. UW-Madison has 44 libraries on the campus. Especially pressing concerns are communication between the numerous branches and reliance on student staffing.

Other participants voiced similar concerns about minimal staffing on evenings and weekends and concerns about ensuring sufficient training for student assistants left in charge of smaller branches. Van Gemert reported that having the UW police department as advisors has established a proactive, col- laborative approach that has been very helpful in addressing security concerns.

Other concems included clearly establishing with employees that even public institutions are not obligated to provide unrestricted access to troublesome or potentially dangerous patrons.

The public services directors also discussed new approaches to gathering statistics. Isabel Sterling (University of California, Berkeley) led the discussion and noted the need to balance simplicity in statistics gathering with the need for meaningful data. The University of California at Los Angeles was mentioned as being engaged in completely revising its statistics for public services and developing new categories for describing interactions with users. The discussion also noted that although some institutions seemed to be experiencing a decline in some traditional reference questions, there has been an increase in the number of questions about hardware and software.

Sally Kalin (Pennsylvania State University) and Tom Wall (Duke University) initiated a discussion about course management software. It was suggested that course management software will dramatically shape the reference environment because it is seen as being a major vehicle for delivery of resources at the point of need and it permits users to be much more self-sufficient.

As various institutions make decisions about course management software, Kalin emphasized the importance of librarians participating in the process of evaluating and selecting this software. Concerns were also raised about the multiplicity of course management software applications at some institutions and that university information technology departments sometimes see selection of software as their territory.

The public services heads concluded the discussion by reviewing possible topics for upcoming meetings: how jobs have changed in public services and issues of recruitment and retention. Janice Simmons-Welburn (University of Iowa) will be the discussion group's new convenor-Jolm Lebner, University ofHouston, jlebner@ub.edu 
cussion on electronic geographical resources, such as evaluating authoritativeness and facilitating interdisciplinary study.-Rebecca R. MalekWiley, TulaneUniversity, malek@tulane.edu

\section{Women and technology}

Joan Korenman, director of the Center for Women and Information Technology at the University of Maryland, Baltimore County, and featured panelist for the Women's Studies Section (WSS) program "Women, Technology and Libraries," reported that although women now make up more than half of online users, they "are still seriously underrepresented as developers of information technology."

In 1998, Korenman started the center with two mutually reinforcing goals: to encourage

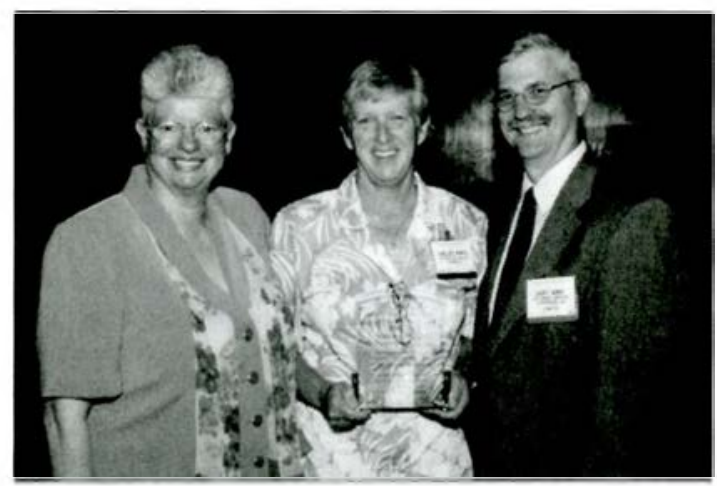

Then ACRL President Mary Reichel and Baker \& Taylor/ YBP's Gary Shirk help this year's Academic Librarian of the Year, Shelley Phipps, show off her award at the ALA Annual Conference.

more women to become information professionals and to be sure that information technology meets women's needs. She highlighted the CWIT Web site (http://www.umbc.edu/ cwit/), which collates news, information, and resources for women in IT.

The other three panelists discussed the ways technology impacts women in the library profession. Kelly Hovendick (Syracuse University) argued that because technology is accorded such high status and cultural cachet, it has the ability to elevate the status and image of library professionals, but only if the female majority of librarians are assertive about the tech roles they are assuming.

Reporting on female library staffers' attitudes toward technological training, Dolores Fidishun (Pennsylvania State Great Valley) re- vealed that they learned best in one-on-one situations with immediate application and handouts for further reference. The need for technology mentors was highlighted.

Kristin Gerhard (Iowa State University) wrapped up the session by looking at barriers women experience when they approach IT, and strategies for overcoming them. She urged: "Our goal is to be technically competent, not comfortable. Notice your zone of discomfort and then push yourself into it."-Jennifer Gilley, Penn State New KensingtonLibrary,jig15@asu.edu

\section{Librarians in the big leagues}

Alliances between teaching faculty and academic librarians were highlighted before a crowd of 75 at the Law and Political Science Section (LPSS) program "Librarians and the Teaching Academy: Are You Ready for the Big Leagues?"

Sallie Ives, director of the Facuity Center for Teaching and eLearning at the University of North Carolina-Charlotte (UNCC), provided an overview of the challenges faced by teaching faculty, including diverse student populations, changes in content area, the demand for information literacy as a liberal art, changes in technology, changes in the cognitive sciences, the need for accountability, and strategies to meet these challenges. She also discussed the advantages of having the Faculty Center for Teaching and e-Learning in the university library and collaborative efforts with librarians at UNCC, and she provided a brief bibliography on the teaching academy.

Linda C. Smith, Susan E. Searing, and Jeni E. Weidenbenner of the University of Illinois Champaign-Urbana (UIUC), discussed the UIUC Alliance for Teaching Excellence and UIUC campuswide initiatives, including the Teaching Alliance, a partnership of the Graduate School of Library and Information Science and the University of Illinois libraries. Participants in the alliance choose the topics that will be investigated. In the first year of the program, they held a retreat to discuss learning styles, brainstorming, and peer evaluations. During the academic year they held sessions on technology, the electronic classroom, exemplary 
teachers, HTML, and effective lecturing. These sessions were held during lunch hours and in cluded peer evaluations. During the next academic year they plan to focus on undergraduate education.

The audience asked several questions about the benefits of having a teaching center in the library, examples of collaboration with librarians, the need to broaden the definition of the scholarship of teaching, and how the teaching center fits into university organization. Other questions involved the marketing of the UIUC Teaching Alliance and the effect of the Teaching Alliance on changing the attitudes of those who attended. Jeanie Welch, Uniuersity of North Cardina-Chantte, jmuelcb@email.uncc.edu

\section{E-research companies}

This year's panelists for the ACRL Distance Learning Section program, offered in conjunction with the Community and Junior College Libraries Section, brought insight to the topic, "E-Research Companies: Value Added or Virtually Redundant?"
Keynote speaker James Neal (Columbia University) called for the development of electronic research tools with wide-ranging functionality and digital collections with interactive capability to meet today's library users' expectations. Neal asserted that e-research companies' current products lack the sophisticated query language and richness of content required to meet students' research needs. The academic library community, according to Neal, is better suited to develop high-quality integrated research services and collections. Yet Neal challenged librarians to create internal and external partnerships with other information leaders and adopt more entrepreneurial business initiatives to achieve their goals.

Troy Williams (founder and CEO of Questia Media) maintained that he was motivated by his own blue-collar upbringing to provide students in resource-poor community colleges, rural areas, and global markets with a high-quality library collection. Williams noted that students value most the functionality, not the content of his product. He markets directly to students

(continuedonpage 574)

\section{Make NO Mistake}

According to a recent readership survey of librarians and higher education faculty:

- $79 \%$ of subscribers polled rely on CHOICE reviews to make their material selections!

- $51 \%$ use CHOICE reviews as their primary collection development tool!

- Compared to 10 other leading review sources, $\mathrm{CHOICE}$ reviews were preferred by 5 to 1 !

\section{- For the best, short critical evaluations of new titles anywhere, readers favored $\mathrm{CHOICE} 8$ to 1 !}

If you purchase material for your college library collection and are looking for exciting new ways to make selecting books and Internet resources easier, faster, and more efficient than ever...

\section{There Is Only One CHOICE!}

\section{Days Online for FREE!}

To try ChoiceReviews.online or our NEW ChoiceReviews.online Site License Edition FREE for $\mathbf{6 0}$ days, click on www. ChoiceReviews.org. To subscribe to $\mathrm{CHOICE}$ Magazine or Reviews On Cards, contact us at www.ala.org/acrl/choice, or call (240) 646-7027.

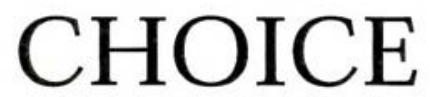

The internationally-acclaimed source of current reviews for academic libraries.

CHOICE is a publication of the Association of College \& Research Libraries, a Division of the American Library Association. 


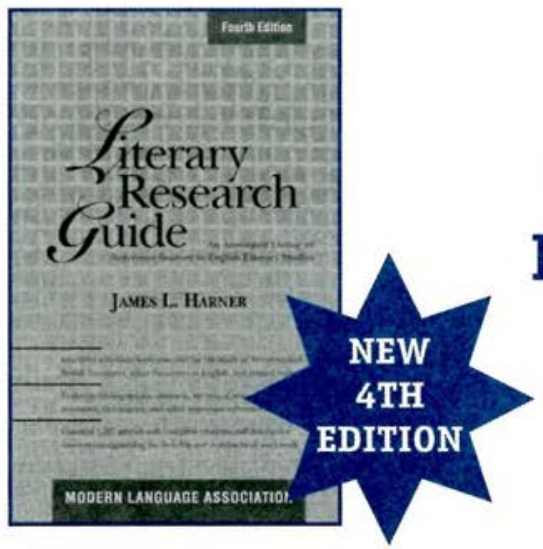

This new edition of the Literary Research Guide adds entries describing resources published since 1997. It also lists reliable Web sites sponsored by academic institutions and learned societies.

The annotations

- describe the type of work, its scope, its major limitations, and its organization

- present parts of a typical entry in the work

- list the type and number of indexes

- evaluate coverage, organization, and accuracy

- explain the work's uses in research

- cite significant reviews

- note related works

The Guide concludes with name, title, and subject indexes.

AVAILABLE JULY 2002

$x \& 820 p p$.

Cloth ISBN 0-87352-982-0

Paper ISBN 0-87352-983-9

\section{A NEW EDITION}

OF THE LEADING RESEARCH GUIDE

IN LITERARY STUDIES

Praise for previous editions

\author{
CHOICE \\ OUTSTANDING \\ ACADEMIC BOOK \\ AWARD
}

"For the serious undergraduate as well as the seasoned scholar, this work is a gold mine of information and a model of its kind."

-American Reference Books Annual 


\section{AUTHORITATIVE.}

PRACTICAL. ESSENTIAL.

The MLA Handbook for Writers of Research Papers is the definitive guide to MLA style.

The fifth edition is a complete toolbox for online research, offering guidance in

- finding research materials online

- judging the quality of information on the Internet

- using expanded and updated MLA formats to document a variety of online sources

- preparing texts in electronic form

xviii \& 332 pp.

LARGE-PRINT EDITION

Paper ISBN 0-87352-975-8

Paper ISBN 0-87352-976-6

The 6th edition of the MLA Handbook will be published in spring 2003.

The MLA Style Manual has been the standard guide for graduate students, teachers, and scholars in the humanities and for professional writers in many fields since its publication in 1985. The second edition features

- added sections and updated guidelines on citing electronic works-including sources from the Internet

- advice for those seeking to publish their articles or books

- a discussion of legal issues, such as copyright and the concept of fair use

- guidelines for the preparation of manuscripts and dissertations

- writing fundamentals

- the fine details of MLA documentation style

xxviii \& 343 pp.

LARGE-PRINT EDITION

Cloth ISBN 0-87352-699-6

Paper ISBN 0-87352-977-4

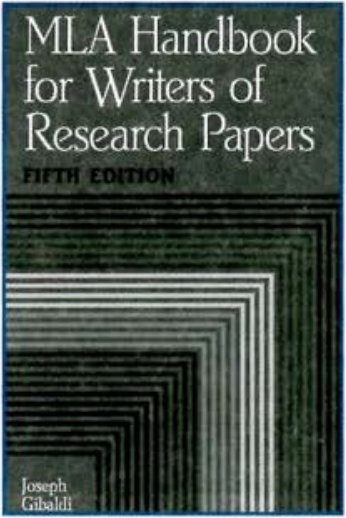

"The style bible for most college students."

-Newsweek

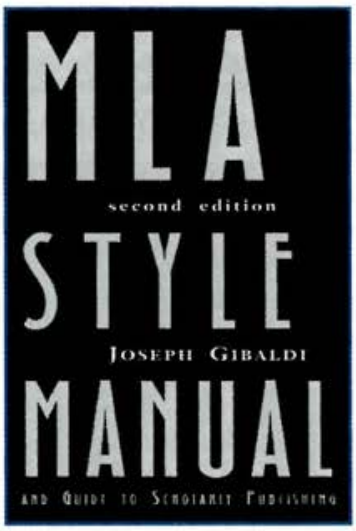

MODERN LANGUAGE ASSOCIATION

PHONE 646 576-5161
26 BROADWAY, 3RD FLOOR

FAX 646 576-5160
NEW YORK, NY 10004-1789

www.mla.org 
priate administrative personnel are kept abreast of the progress that is being made on preservation projects.

The PA must also have strong leadership skills and be self-motivated. This means accepting the responsibility for providing the necessary energy and leadership to get preservation programs started. It also means having the discipline and determination to see projects through, despite distractions that may arise in the libraries where the services are being of fered.

Because many preservation activities are important, but not urgent, it is often tempting for library staff to allow preservation-related duties to get moved to a back burner and never get picked up again. It is the PA's job to provide the leadership and motivation necessary to keep this from happening. He or she must clearly demonstrate, by example, how to complete tasks on time and follow up regularly with preservation team members to ensure they are meeting their obligations.

Despite all this, the PA must be flexible and adaptive. Procedures that work in one library may not work in another. The PA should have the experience necessary to recognize what will and will not work and be dynamic enough to adjust an agenda to meet the specific needs of individual libraries.

Few people naturally have the skill sets necessary to effectively administer preservation programs at more than one institution at a time. However, these skills can be learned just as other management skills are learned.

\section{Final thoughts}

The idea of libraries acquiring part-time preservation expertise is certainly not new. Service bureaus around the country offer such services to libraries on a regular basis. ${ }^{4}$ While these programs are excellent, a consortial agreement between libraries allows participating institutions to have access to preservation expertise on a more regular and consistent basis.

In many research libraries, PAs have accepted additional job duties as needed by their institution. Instead of capturing time from the PA to accomplish other library duties, institutions should consider opportunities to offer preservation services to neighboring libraries unable to support these needs for themselves. The KU-KSU model is just one example of how this can work well. Establishing consortial preservation management agreements has great potential that should be investigated in earnest by more research libraries.

\section{Notes}

1. Julia Blixrud, "Preservation Expenditures Level; Microfilming, Staffing Decline," $B i-$ monthly Neusletter of Research Library Issues and Actions, Issue 201 (December 1998). See the ARL Web site at http://www.arl.org/newsltr/ 201/stats\%2Dpres.html.

2. Mary Jo Lynch, "What we Now Know about Librarians," American Libraries 31 (February 2000): 9.

3. See the University of Kansas Libraries' Preservation Department Web page for more information about this service at http:// www2.lib.ku.edu/preservation/.

4. For example, see the Regional Alliance for Preservation Web page at http:/ www.rap-arcc.org.

\section{("ACRL in Atlanta" continued from page 565)}

willing to pay $\$ 20$ a month for Questia. Williams is pursuing global markets where he envisions the Questia product bundled with required textbooks.

Morris Shephard (chief marketing officer of Knowledge Ventures) described his development strategy: to produce nonfrustrating research tools that keep students interested at teachable moments and that enable teachers to retrieve sources quickly, thus attaining credibility with their students. Shephard promoted emerging partnerships between libraries and knowledge industries and blasted textbook publishers as wrong-headed old losers.

Susan Swords Steffen (Elmhurst College) reported on a pilot project with Questia at her library. Students who used Questia were disappointed with their search results, but they were unaware of the superior database products available to them via proxy campuswide. Steffen implored librarians to market their services more effectively and take a proactive role with vendors to make library database products more accessible and convenient to use-Claudia Sbon; GwinnettUniLersity CenterLibram, csbom@ guc.usg.edu 